\title{
Small mining and exploration enterprises in the Urals
}

\author{
Vladimir Boltyrov*, Lyubov Storozhenko, Sergey Degtyarev, and Tatyana Bobina ${ }^{1}$ \\ Ural State Mining University, 620144, Kuibyshev st., 30, Ekaterinburg, Russia
}

\begin{abstract}
The article describes small mining and exploration enterprises in the Urals, some considerations are put forward to improve procedures of commercialization of natural and man-made facilities to be used by the small enterprises.
\end{abstract}

\section{Introduction}

According to data provided by the Russian Federal State Statistics Service, the share of small business in Russia as of 2019 was $18-20 \%$, and this economy sector employed from 8 to 15 million people, according to different estimates. In the advanced economies the small enterprises provide up to $50-60 \%$ of GDP, and employ up to $70 \%$ of the population. As regards the small mining and exploration enterprises, the situation is more depressing here: this is just $1.5-2 \%$ of the Russian GDP. Only artisanal gold mining, which was developing and prospering during the USSR can be referred to in this regard.

However, when Russia was introduced to the market economy in the 90s, it was believed that small mining and exploration enterprises would emerge and reach prosperity. K.N.Trubetskoy, Academy Fellow, pointed out in his report at the Parliament hearings in the State Duma in October 2001 that small mining business should play a special part in microentrepreneurship, "since it has a few specific features distinguishing it from other small enterprises" [1].

\section{Materials and methods}

At that time, we introduced a discipline "Geology and subsurface management" within specialization "Geological survey and mineral exploration" at the Ural State Mining University and started training the new generation of minerals developers. It was assumed that they would pioneer the emergence of the small mining and exploration enterprises in Russia.

The USA experience indicates that the number of small mining and exploration enterprises employing up to 20 people amounts to $70-80 \%$ of total number of enterprises in the industry since long ago (since the 80 s of the last century).

\footnotetext{
*Corresponding author: glzchs@mail.ru
} 


\section{Results and discussion}

Today, when inventory of mineral deposits discovered during the USSR is exhausted, and there are no new discoveries (except for those in oil and gas sector), the world of small deposits is expected to advance. It is common knowledge that it is acceptable to categorize commercial mineral deposits, based on their scale, as unique, giant, medium and small ones. According to V.I. Krasnikov, the following ratio of mineral deposits is estimated for the most common metals: $7 \%$ of giant deposits of total quantity, $23 \%$ of medium deposits, and $70 \%$ of small deposits. The USSR centrally planned economy focused on medium and giant mineral deposits, for it was easier to fulfill the reserve increment plan at their expense. The small deposits were not even accounted for in the national register.

At the same time, quite a strong mathematical relationship exists between number of the mineral deposits and the amount of mineral resources reserved therein: the larger the deposit, the less frequently those minerals occur, and the other way around. This way, let us call undiscovered potential resources of a certain ore district - Q, field reserves - P, and the number of deposits $-\mathrm{n}$, then the specified relationship can be expressed as equation (1) below.

$$
\mathrm{Q}=P n=\mathrm{const}
$$

For example, if the gold reserves in specific ore district amount to $30 \mathrm{t}$ at least, i.e. $\mathrm{Pn} \geq$ 30 , about 10 small deposits of $3 \mathrm{t}$ gold reserves can be expected, and 6 deposits of $5 \mathrm{t}$ reserves etc. [2].

In order to help entrepreneurs to go into their business in the scope of small mining and exploration enterprises, we published a workbook titled "Geology for natural resources management" via "Nedra" Press for them in 1995, at the same time we published training aids "Basics of small business in geology" for our students [2,3].

These workbooks characterized the terms and ventures of business in Russia, offered guidelines for making business plans and making financial decisions, small business administration tools, and outlined the main scopes in natural resources management: development of small primary and placer deposits, stone-cutting production, art of stonework, collectibles, geology tourism.

Production and processing of natural quartz can be a promising business for small mining and exploration enterprises.

Three main form of quartz can be found in nature: idiomorphic crystal (rock crystal, amethyst, cairngorm, morion, citrine quartz), granular aggregate without specific crystallographic cutting (rock-forming quartz, quartz of pegmatite and quartz veins of different origin), fiber and fine grain formations filling cavities (calcedony, agates). The latter are mainly used in jewelry and stonecutting.

Requirements for acceptability of rock crystal for melting transparent vitreous silica are specified in Industrial Standard OST 41-07-152-66, which regulates amount of fault-free sections (free of gas and fluid inclusions) in 10-60 mm pieces, and specifies maximum permissible concentrations of some chemical elements (impurities). Mineral spots in this material are not permissible.

Gangue quartz is a more standard and commonly known form of natural quartz. It represents aggregated individual grains without crystallographic cutting of their own and separated by composite surfaces. The properties of boundary surfaces, grain shape and size, their chemical composition, degree of transparency of quartz are determined by conditions of its origination, growth and further natural transformations in the system: individual geological body (gangue) containing the minerals.

The main parameters characterizing the quality of natural quartz are its chemical purity and mineral composition, and transparency. 
Expected progress of economic revival would again generate higher demand for high quality raw quartz in Russia and its production and processing in terms of initial scope, i.e. production of middling product at the mining plant followed by re-processing can become an attractive scope for concentration of efforts of small mining and exploration enterprises.

Stone processing industry is another promising scope for the small enterprises.

Human kind has been using the natural stone since evolution of apes into human beings. The scope of application of the natural stone expanded with the global progress and the $21 \mathrm{st}$ century can be hardly thought of without lapidary, jewelry-ornamental, and tiling natural materials (raw gemstones).

The standard process used for giving a stone required shape, size and face surface structure consists of some operations. The state-of-the-art techniques would enable the stone processing industry to use various rock processing methods for stone processing (Fig. 1).

The term "stone" ("natural stone") is applicable to subsurface rocks used by humans for applied purposes since long ago. These rocks, extracted from the earth interiors in form of rock masses-blocks and in form of plates rarely, represent the source raw materials for fabrication of tiling materials as well as architectural and construction, monumental (statuary) and some commercial-grade items.

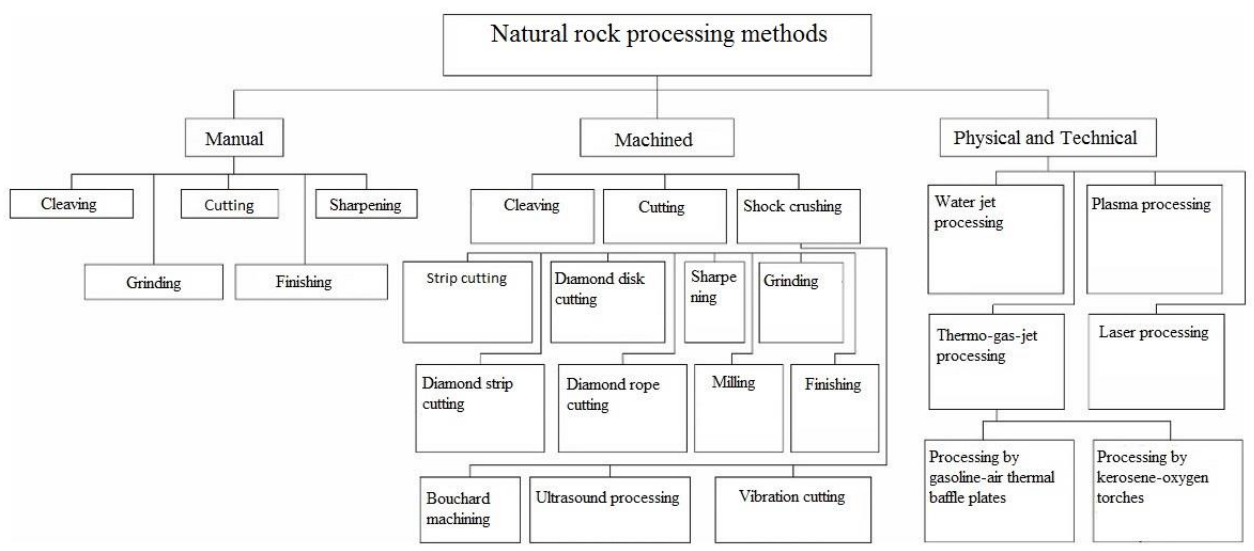

Fig. 1. Classification of natural rock processing methods used at production of ashlars and finished items

Stone processing industry is a multistage and quite complex one from administration perspective. Nevertheless, it opens wide field for small enterprises, especially those manufacturing smaller size tiling of gem stones (rhodonite, blue elvan, jasper at el). Construction of such production facilities does not require much space, high diversity of machines and equipment, heavy duty hoisting equipment, and too many contractors, obviously.

Art of stonework is another scope of small mining and exploration enterprises.

Stone is perfect material for applied arts, its indispensable for sculptor and architect. The gemstone works were always very popular and remain in high demand.

The range, design, shapes, sizes and processing methods of gemstone works are much diversified. Small stones inserted in jewelry, large marble pieces of art, simplest cabochons and fine entails, utilitarian household articles and magnificent pieces of architecture and decoration can be found among these works.

Based on process features, production of articles fabricated of raw gemstones is divided into lapidary work, decorative lapidary stonework, artistic lapidary stonework, tiling and monumental decorative (Fig. 2). 


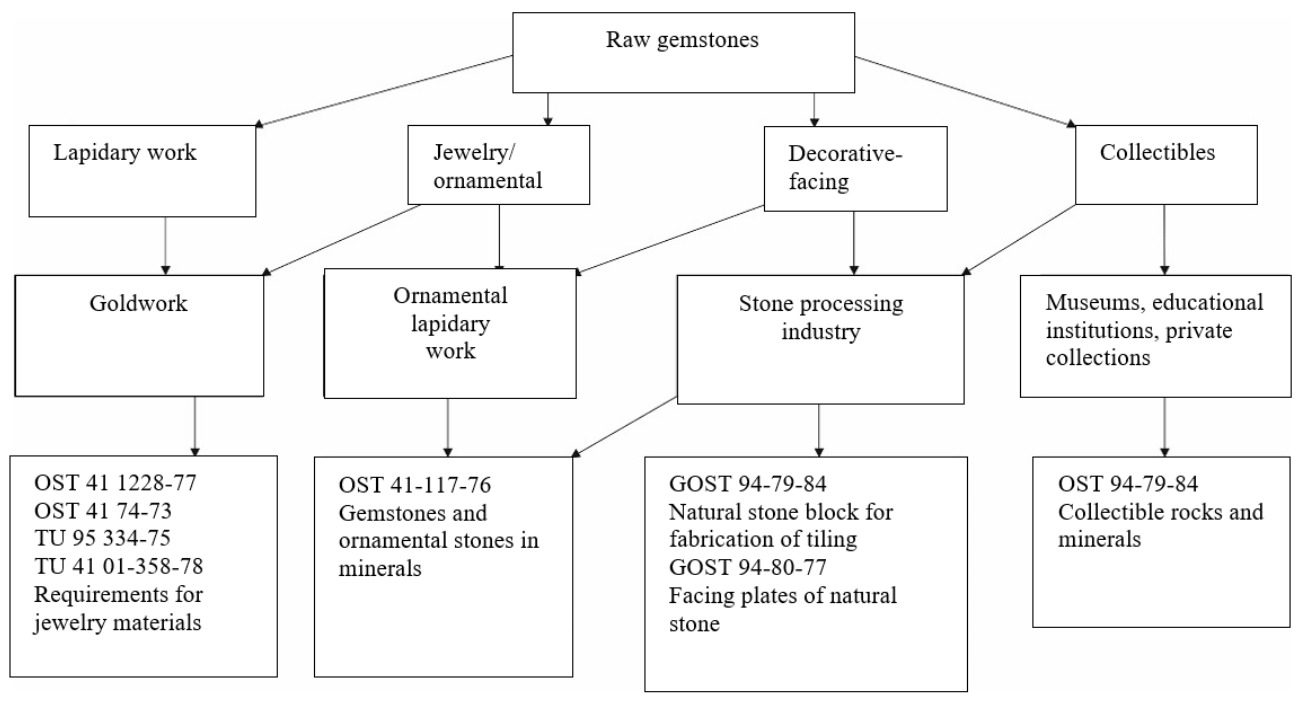

Fig. 2. Classification of raw gemstones for manufacturing objects of art

Small enterprises play a major part in production and processing of raw gemstones in the market economy. This is caused by economic factors, included but not limited to readiness of small enterprises to quick rearrangement of their production in conjunction with the market conditions, comparatively low costs of administrative and management personnel, ability to hire highly qualified experts with specific gifts, which expands the range of articles to be manufactured. It should be highlighted that only small enterprises producing and processing raw gemstones are able to quickly commoditize comparatively inexpensive articles made of gemstones. A wide range of articles made of raw gemstones can be achieved only, provided that the market offers a wide choice of jewelry and ornamental materials, which are unevenly distributed in nature.

Obviously, small mining and exploraiton enterprises can't overlook collectibles, rocks and ores.

With regard to collectibles, it should not go without mention that natural resources must be protected from common "mineralogical poaching". It should be kept in mind that mineral resources are property of the state in our country, and collectible stones fall within this property as valuable minerals. Pillage and ineffective extraction of rare gem minerals result in permanent loss of unique artefacts.

Before starting collection of the minerals, rocks and ores, guidelines regulating their acquisition procedures must be studied carefully.

First of all, it should be taken into account that collection of the first-class precious stones (diamond, emerald, true ruby, sapphire, alexandrite), as well as precious metals (gold, silver, platinum group elements) is prohibited in the Russian Federation without special permission.

However, it is permissible for stone collectors to restock their collections for nonmerchandising purposes with single units without obtaining a permission for retrieval of collectibles.

Secondly, commercial production and collection of any minerals, rocks and ores at any natural sites is permissible only provided the license is issued for collection of mineralogical and other geological collectibles. Violation of this established procedure incurs administrative and criminal liability.

Every federal subject of the Russian Federation has a department of mining and geology at its administration, which issues licenses and supervises their proper observation. 
Finally, geological tourism that small mining and exploration enterprises can develop should be highlighted.

Geological tourism is waiting for its organizers.

Needless to say, treatment of mining wastes should also be added to the scope of business objectives of small mining and exploration enterprises.

This way, more than 8.5 billion tons of mining, enrichment, metallurgical, power and chemical production wastes have been aggregated over 300 years by the Sverdlovsk Region alone. 188 man-made sites of different types of minerals were founded.

The mining wastes challenge can be approached from different perspectives: economical, resource, technological, managerial, legislative, social, environmental, humanitarian, HR.

From the resource potential perspective, the mining wastes can surely be considered an additional good source of replenishment of raw materials and minerals base. In fact, the mining wastes of fields with nonferrous and precious metals contain the following components (with specified concentrations): more than 8 million tons of copper, more than 9 million tons of zinc, more than 1 million tons of lead, 2.5 million tons of nickel, 33.5 million tons of aluminum oxide, 600 thousand tons of tin, 200 thousand tons of molybdenum, one thousand tons of gold, 12 thousand tons of silver. The concentration of iron in wastes of iron and steel industry is often higher than $30 \%$, so these wastes can be considered secondary iron ore raw materials.

The question still stands about their extraction. Which is the right legislation to follow: The Federal Law "Concerning Subsurface Resources" adopted in 1991, or the Federal Law "Concerning Production and Consumption Waste" adopted in 1998? Everything depends on who owns those wastes, whose property the mining wastes are. If the mining wastes are property of still acting mining plant, they can treat the mining waste as standard production waste and should be able to start extracting the valuable components (for example, by heap leaching) without being subjected to licensing. A man is the king in his house, as the saying goes. There is some experience of treatment of in-house wastes my major companies in the Russian Federation. In particular, the in-house wastes are effectively processed in the Murmansk Region at Olenegorsk mining and processing complex (OJSC "Olcon"), Kovdorsky mining and processing complex (SC "Kovdorsky GOK”), JC “Apatit”, OJSC "GMK Pechenganickel", et al [5].

In addition, it is not always that the mining wastes treatment is associated with status of man-made field and feasibility study of design requirements. More than 58 million tons of different wastes were processed in the Middle Urals in terms of the Program "Development of man-made mineral formations in the Sverdlovsk Region" in 1997-2003, and the cost of product amounted to 18 billion Rubles [3,5].

This way, the current slag dumped by copper melting industry is processed with production of copper concentrate at OJSC "SUMZ" due to lack of resources. The in-house slag dumps are used as raw materials by the metal plant named after A.K. Serov, an old slag dump processing unit is operated at the Kuvshinsky mill roll plant, the Alapayevsk metallurgic plant is using blast-furnace slag to produce high quality abrasives. Appraisals indicated that the dumps of Ural iron and steel industry contain about 9 million tons of iron, and about 1.5-2 million tons of metal are recovered from blast furnace and steelmaking slags every year.

A new program focused on man-made waste treatment is prepared for adoption in in the Sverdlovsk Region. It is planned in terms of this program to process 110 million tons of dumped wastes with production of more than 2 million tons of ferrous metals concentrate, 120 thousand tons of copper concentrate, and 5 thousand tons of rare earth metals by the year of 2030 [4].

However, if the mining wastes are represented by so called "mature tailings" generated as a result of earlier mining, then, as per the Federal Law "Concerning Subsurface 
Resources", any dump shall be viewed as field of subsurface resources, and once the new owner of the mining wastes procures the license for geological survey of subsurface resources with further development of the mineral, they are bound to conduct economic-geological evaluation of reserves, i.e. alternatively accomplish the following stages of the man-made field (MF) development: conduct geological exploration, estimate mineral resources, validate them at the National Reserves Committee of the Federal Subsoil Management Agency, enter them in the national register; and start development of the field only after the man-made deposit status is assigned to it [7].

This way, the small venture LLC "GRK "MONOLIT" made a decision about development of the man-made field "Dumps of Allarechensky Field" in 2006, when the nickel prices were high [8]. Official estimation of forecast resources was 250 tons of nickel. The LLC "GRK "MONOLIT" was charged 6.5 million Rubles in prices of 2006 for the use permit for "Dumps of Allarechensky Field". Further, according to the Federal Law "Concerning Subsurface Resources", the enterprise bound by the license agreement shall perform stage-wise geological exploration of MF. The first stage - conducting audit and appraisal operations, based on which results the assessment of mineral resources must be made, and the feasibility study of MF development shall be presented. The second stage exploration efforts with estimation of reserves and providing feasibility study of design requirements with entering the reserves in the national register. Naturally, in accordance with existing requirements, each stage of geological explorations must be associated with frontend engineering and design in conjunction with mandatory approvals and expertise of design documents established for such cases. In spite of extensive scope and workload, these operations are ineffective, which, in most cases, is inherently caused by their poor quality. In addition, engagement of small mining enterprises with mining waste processing is considerably hindered by some market and legislative factors, thereby making the mining waste processing projects less appealing as an investment for such enterprises. For example, the cost of geological exploration has major impact on resulting investment efficiency of MF development, and their duration is comparable with life of the site itself, and in some cases, can be longer than that (e.g. at legacy placers processing). In this context, the relevancy of requirements specified by the Federal Subsoil Resources Management Agency concerning entering the MF reserves in the national register and monitoring their flow raises some questions. As a rule, the man-made filed reserves are scarce (a few thousand tons) vs. primary subsoil resources (amounting to millions of tons) taken into account by the national register, and it has no effect on assessment of strategic potential of the country in conditions of crossborder business conducted by most of mining and metallurgical companies.

Design complexity due to exclusive requirements applicable to mining industry, and requirement to follow all regulatory prescriptions, increase the cost and time required for commissioning stage of the site considerably. In addition, a small enterprise ranking as a mining company developing MF is not entitled to government support during research and implementation of innovative technologies, which support is provided by the Federal Law "On the Development of Small and Medium-Sized Enterprises in the Russian Federation". Furthermore, they lose tax privileges provided by the Federal Law "On Protection of Environment" to the enterprise classified as waste treatment plants. Therefore, the Federal Law "Concerning Subsurface Resources" appears to lack foresight, which makes development of man-made mineral formations much less appealing to potential investors.

This way, an example of the "Dumps of Allarechensky Field" as development of manmade mineral fields suggests that man-made mineral field development projects are complex subject matters of economic assessment. Success of projects focused on processing "mature tailings" (man-made fields) calls for establishment of certain institutional conditions, included but not limited to special governmental regulation. The legislation must provide 
conditions facilitating commissioning of such projects according to simplified procedure in shorter terms, as far as the market situation is favorable $[8,9,10,11]$.

Since "mature tailings" of the mining industry are not always of interest to major mining business recently, involvement of smaller mining enterprises with such waste treatment processes is required.

Because the project of development of the "Dumps of Allarechensky Field" was never implemented in spite of financial and time costs incurred by LLC "GRK "MONOLIT", a conclusion can be made that the legislation of the Russian Federation and existing institutional environment hinder implementation of mining wastes processing projects by the small mining enterprises.

What happened to the dumps of Allarchinsky field today? Over 48 years of abandoned dumps at least $1 / 5$ of nickel and copper reserves migrated into the environment from them, which turned the surrounding land into man-made wasteland, having inflicted environmental damage of total 3.5 billion Rubles, while economic damage amounted to 600 million Rubles [12].

Deterioration of then rich dumps of the Allarchinsky field is in progress today; and galloping inflation of reserves and large-scale pollution of environment are going alongside. The mining waste field performance is devastated, and it remains a source of chemical pollution of environment.

Only small enterprises like the abovementioned LLC "GRK "MONOLIT" are able to develop abandoned mining waste fields not accounted for in the inventory of effective mining plants, as soon as they get a chance to work comfortably and cost-effectively, provided appropriate amendments are made in effective legislation, provided some preferences are granted to investors, and thousands of abandoned mining waste fields up to this day will be commercialized, replenishing the country's exhausted raw-materials base of rare metals and improving the environment over territories occupied by active and abandoned mining enterprises.

Therefore, it is worth to subscribe to opinions voiced by the leading experts $[13,14,15]$, that "small and medium sized mining companies can become the drivers with capacity to reanimate and give momentum to revival of the country's mining industry" [13]. To this end, an opportunity must be provided for the small and medium sized mining and exploration companies to obtain permission for development of MF. Expensive procedures of geological evaluation of reserves of minerals must be discontinued. In addition, the accuracy of such evaluation is very poor for MF, as shown above. Let the enterprise take over the authority. The license fee should be subjected to post factum estimation, when an enterprise completes operation of MF. Otherwise, the license fee can be estimated as a fixed percentage of the cost of valuable component produced from MF over the entire service life (or for every year with annual fee). Implementation of such procedures would enable the small mining enterprises to save precious time of high prices of produced resource and to avoid overinvestments that may not necessarily pay back.

Herewith, the state should establish environmental criteria for MF processing projects. Proven reduction of contaminants released into environment upon completion of project implementation can be deemed such a criterion.

Thus, implementation of projects of man-made fields development must be associated with simplified procedures of their commercialization, and introduction of tax privileges. The legislative system, government support, creation of investment environment for projects focused on processing of aggregated mining wastes would be helpful for enabling comprehensive processing of produced minerals, increase cost effectiveness of the mining complex of old industrial regions, and increase their environmental safety. 


\section{Conclusion}

Unfortunately, as far as the Russian legislative effective for management of subsurface natural resources maintains its punitive and fiscal character, until redundant administrative barriers are eliminated, until the roles of the state and private enterprises in subsoil management are segregated, existence of small mining and exploration enterprises will remain declarative only. Notwithstanding, the Russian President V.V. Putin shared this message: "If all barriers are removed and active development of small business in geological exploration is to be enabled, we would manage to fill a gap in this scope of economy." President V.V. Putin shared this message in connection with the chance of emergence of so called junior geological exploration companies, which could focus on geological surveys of subsurface resources and discovery of new mineral deposits, attraction of investments, and technological development in geological exploration. All that applies to small mining and exploration enterprises, which could be engaged with management of the mining wastes and other businesses listed above.

The small mining and exploration enterprises will bring flexibility to our economy, mobilize financial and manufacturing resources of society, will gain anti-monopoly potential, address the challenge of employment of population and other social issues of the country.

\section{References}

1. K.N. Trubetskoy, M.E. Pevsner, The Mining Journal, 3, 8-13 (2002)

2. V.B. Boltyrov, A.F. Fadeichev, V.I. Leshchikov, S.I. Biryuchev, Geology for user of mineral resources (practical guideline for businessmen): Objects and conditions of mineral resources management, 156 (Moscow: Nedra Press, 1995)

3. V.B. Boltyrov, O.V. Zhukov, Yu.A. Polenov, A.F. Fadeichev, Basics of small business in geology. Part 1. Main scopes of business in geology and mineral resources management: Training aid, 180 (Yekaterinburg: Ural State Mining University Press, 1998)

4. A.I. Semyachkov, V.V. Kuchin et al., Environmental and technogenic safety of mining regions: Papers of VI International research-to-practice conference 10 April 2018, 267284 (Yekaterinburg, 2018)

5. S.G. Seleznev, Management and legal aspects of the Russian legislation in management of the mining wastes, Issues of effective use of the mining wastes: Proceedings of the Russia-wide Conference (Moscow, 2013)

6. S.I. Mormil, V.L. Salnikova, L.A. Amosov, G.G. Khasanova, A.I. Semyachkov, B.B. Zobnin, A.V. Burmistrenko, Man-made deposits of the Middle Urals and assessment of their environmental impact, 206 (Yekaterinburg: NIA-Nature, 2002)

7. S.G. Seleznev, N.A. Stepanov, The Mining Journal, 5, 32-40 (2011)

8. S.A. Lipina, L.K. Bocharova, L.A. Belyaevskaya-Plotnik, Journal of Mining Institute, 230, 217-222 (2018)

9. T.V. Ponomarenko, R. Wolnik, O.A. Marinina, Journal of Mining Institute, 222, 882-891 (2016)

10. M.A. Nevskaya, O.A Marinina, Academy of Strategic Management Journal, 1, 149159 (2016)

11. M.A. Nevskaya, O.A. Marinina, Regulatory aspects of mining waste management in the Russian Federation Biosciences Biotechnology Res Asia, 12(3), 2619-2628 (2015)

12. S.G. Seleznev, V.B. Boltyrov, The Mining Journal, 7, 57-64 (2013)

13. E.P. Volynkina, Herald of Siberian State Industrial University, 2, 43-49 (2017)

14. V.V. Glotov, P.P. Petrovsky, O.V. Postnikova, The Mining Journal, 303-308 (2014)

15. E.I. Panfilov, Mine surveying and subsurface resources management, 2, 15-22 (2001) 